\title{
Predictive models of early motor development in preterm infants: a longitudinal-prospective study
}

Open acess

1'Departamento de Fisioterapia e Educação Física, Universidade Estadual de Goiás, Brasil.

${ }^{2}$ Programa de Bolsa de Incentivo à Pesquisa e Produção Científica (PROBIP) da UEG.

${ }^{3}$ Departamento de Neurociências e Ciências do Comportamento,

Faculdade

de Medicina de Ribeirão, Universidade de São Paulo, Brasil.

Corresponding author:

cibellekayenne@gmail.com

Manuscript received: 01 May 2017

Manuscript accepted: 10 July 2017

Version of record online: 06 September 2017
Cibelle Kayenne Martins Roberto Formiga ${ }^{1,2}$, Martina Estevam Brom Vieira ${ }^{1,3}$, Rayne Ramos Fagundes ${ }^{1}$, Maria Beatriz Martins Linhares $^{3}$

\begin{abstract}
Introduction: Preterm infants are vulnerable to developmental delays. Detecting problems at an early age is one of the challenges of professionals and researchers in the area.

Objective: To analyse the motor development and to identify the risk factors associated with predictors of overall and motor delay in preterm newborns.

Methods: Eighty preterm infants (50\% female; mean gestational age $=33 \pm 2.2$ weeks) with low birth weight (average of 1,715 $\pm 437 \mathrm{~g}$ ) were evaluated using the Neurobehavioral Assessment of the Preterm Infant (NAPI) during the neonatal phase (prior to term age), the Denver Developmental Screening Test II (DDSTII) between 2 and 8 months, the Test of Infant Motor Performance between 2 and 4 months regarding motor development and the Alberta Infant Motor Scale between 4 and 8 months.

Results: Neurobehavioural delay was noted in $24 \%$ of the infants in the neonatal phase. Between 2 and 8 months, the delay in overall development was $\geq 31 \%$ and the delay in motor development was 35-36 \%. Decreased levels of alertness, orientation, motor development and vigour according to the NAPI were shown to be predictive of a delay in development between 4 and 6 months of age. The delay in overall development between 2 and 6 months was predictive of a delay in motor development between 6 and 8 months.
\end{abstract}

Conclusion: Neurobehavioural variables, hospital stay and overall delay are good predictors of motor development during the first year of age.

Keywords: preterm, motor development, infants, predictive model 


\section{INTRODUCTION}

The development of preterm infants is influenced by gestational age (GA), birth weight, and clinical and social risk factors ${ }^{1,2}$. GA and birth weight are highlighted as the main biological variables that determine risk to healthy growth and development of infants ${ }^{3}$. With the advances in perinatal medicine in recent decades, survival rates among preterm infants have increased considerably ${ }^{4}$. However, these surviving infants remain at risk due to greater motor, sensorial, behavioural, cognitive and health problems than among children born at term ${ }^{5,6}$.

Short- and long-term predictive studies in preterm infants have largely focused on the most immature $(<33$ weeks) and lowest-birth-weight $(<1,500$ grams at birth) children ${ }^{7,8}$. The prediction of development continues to be a challenge for researchers, particularly in the early postnatal period. Greater efficiency in predicting the risk of development may improve the selection of eligible infants for early therapeutic strategies ${ }^{9}$.

Several predictive studies have been performed using neonatal and maternal risk factors to predict the outcome of development in preterm newborn infants at different ages $^{10-14}$. However, these studies did not mention the use of neurobehavioural responses of premature newborn infants in the neonatal period (prior to term age) to predict global and motor outcomes prior to the end of the first year.

Evaluating aspects of the development of preterm infants when they are still in hospital would be a precautionary approach in studying the trajectory of these children. Knowing that the preterm infant is exposed to some level of discomfort related to their stay in the neonatal intensive care unit (NICU) and that these stimuli can, therefore, cause neurobehavioural adaptive responses to stress ${ }^{15}$, it is necessary to evaluate long-term behaviour, comparing their responses in the first weeks of life and in subsequent months of development.

The impact of risk factors on the development of preterm infants has led to the use of assessments of different types, such as developmental screening and motor development assessments, to detect problems in the development of these infants. The aim of such screening is to identify infants with developmental delays and carry out an adequate referral ${ }^{16}$. Standardized assessments of motor

\section{METHODS}

\section{Study design}

Prospective longitudinal study.

\section{Participants}

The sample consisted of 80 infants $(50 \%$ female and $50 \%$ male), born preterm ( $<37$ weeks' gestational age) and underweight $(<2,500$ grams $)$, evaluated during the first eight months of post-conceptional age. Inclusion criteria were as follows: infants with no congenital anomalies and who were clinically stable on the first day of assessment for data collection. In the case of twins, only one was included by random selection.

From an initial group of 190 preterm infants who were born at the Hospital Materno Infantil in the city of Goiânia (State of Goiás, Brazil), 147 were evaluated in the first postnatal weeks (prior to term age) during hospitalization in the Intermediate Neonatal Care Unit (Level II). Of these 147, 80 completed the follow-up programme from birth to eight months of age. The sample loss (54\%) was mainly due to the difficulty in locating families to schedule follow-up appointments for infants at risk. development in the neonatal period may predict the risk of cerebral palsy at the end of the first year of life ${ }^{17,18}$.

Motor development assessment has been identified as having a high predictive value in detecting developmental delay in infants at risk of, and with, cerebral palsy in the long term $^{19}$. In addition, not only has extreme prematurity led infants to experience delays and sequelae, but moderately preterm infants (32-36 weeks' gestation) have shown delayed motor development when associated with the low socioeconomic status of their families. The economic factor can increase the risk of prematurity and its consequences for an infant's health ${ }^{20}$.

Preterm infants born between 29 and 36 weeks have a higher risk of undergoing changes in their neurological development, including intellectual, behavioural and language disorders as well as educational problems, than fullterm infants do. Thus, it is important to use tools to track child development in public health services to predict children's predisposition to neurodevelopmental delay ${ }^{21}$.

Across different countries, the number of children with some delay varies, as well as the most affected areas of development. In countries that rank low on the Human Development Index (HDI), there is a higher number of children with developmental delay. The importance of conducting trials to identify disabilities, even discrete ones, to enable interventions and avoid even more significant delays throughout the development of such children should be noted ${ }^{22}$.

Predictive studies on moderately preterm infants born in developing countries need to be carried out to clarify the predictor effect of neonatal care in the short term. Thus, the use of risk-screening tools constitutes a simple and inexpensive tool for detecting delay, especially in developing countries, such as Brazil. Furthermore, assessment in the neonatal period before the baby reaches term age can become a valuable tool for predicting problems in development in the short and medium term.

Thus, the aim of the study is to analse the motor development and identify the risk factors associated with the predictors of overall and motor delay in preterm newborns.

This is a tertiary hospital of the public health system for lowincome population assistance. Most of the participants' families (95\%) were classified as having low socio-economic status. Data were collected over a two-year period (2004-2006).

The sample that did not participate in the study (S-OUT) was similar to the study sample (S-IN) in the following variables: gender (S-OUT: $54 \%$ male; S-IN: 50\% male; $\mathrm{p}=0.62$ ), mean gestational age (S-OUT: 33 weeks; S-IN: 33 weeks; $p=0.56$ ), average birth weight (S-OUT: 1,684 g; S-IN: 1,715 g; $p=0.75$ ) and length of stay in hospital (in days) (S-OUT: 31 days; S-IN: 29 days; $p=0.79$ ).

\section{Ethical approval}

This study was approved by the Ethics Committee in Clinical Research of the Hospital Geral de Goiânia (Brazil). Informed consent was obtained from parents prior to their participation in the study (protocol number 73/04). 


\section{Instruments and measures}

\section{Neurobehavioral Assessment of Preterm Infants (NAPI)}

The NAPI is a standardized test for neurobehavioural assessment in the early neonatal period. It measures neurobehavioural performance in preterm infants from 32 weeks post-conceptional age (PCA; gestational age plus chronological age) until term age (38-40 weeks). This instrument includes seven clusters: scarf sign, motor development and vigour, popliteal angle, alertness and orientation, irritability, cry quality and percentage sleep. Measures of infant performance in each domain range from zero to 100 points $^{23}$. The highest score corresponds to the best performance in neurobehavioural development in all areas, except in the percentage sleep ratings. Early risk of abnormal neurobehavioural development is assigned when the scores are 1 standard deviation (SD) below the mean. The validity and sensitivity of the NAPI are described using an index of neonatal clinical complications. The inter-rater reliability coefficient ranges from 0.67 to 0.97 , sensitivity $(75 \%)$ and specificity $(69 \%)^{24}$.

\section{Denver Development Screening Test II (DDST-II)}

The DDST-II is a developmental screening test that can be used on children from birth to the age of six. It consists of 125 items, divided into four areas: personal social, fine motor adaptive, gross motor and language. Some items are applied by asking the child to perform specific tasks or through parents/carers, who are asked to report on the infant's performance. The inter-rater reliability and the test-retest reliability ${ }^{25}$ was $\geq 0.75$. The performance was classified as Normal (an item with caution), registered as zero, or Risk ( $\geq$ two items with caution or $\geq$ an item with delay), registered as 1 .

\section{Test of Infant Motor Performance (TIMP)}

The TIMP is a standardized normative test that assesses postural control and selective control of movements required for functional motor performance in infants aged between 34 weeks post-conceptional age and 4 months $\mathrm{CA} .{ }^{26}$ The content validity was 0.83 for the level of maturity and 0.85 for the clinical risk. The predictive validity of the TIMP for development at 12 months on the Alberta Infant Motor Scale (AIMS) was $0.88^{27}$. The inter-rater reliability was 0.94 and the test-retest reliability was 0.89 . It was considered delayed motor development when the score was ranked below average (1.0 SD below the mean), according to normative data ${ }^{26}$.

\section{Alberta Infant Motor Scale (AIMS)}

The AIMS assesses infants' weight-bearing, posture and anti-gravity movements in four positions from birth to 18 months CA. Previous studies showed that the AIMS has an inter-rater reliability $>0.96$ and a test-retest reliability of 0.86 and 0.99 . The concurrent validity ( $8-13$ months) with other standard motor assessments (e.g. the Peabody Development Motor Scale and Bayley Scales) ${ }^{28}$ ranged from 0.84 to 0.99 . Sensitivity ranged from $76 \%$ to $86 \%$ and specificity ${ }^{29}$ ranged from $82 \%$ to $93 \%$. As regards the percentile, infant motor development can be classified as abnormal ( $<10$ th percentile). The score for each position is added to obtain a total gross score, which is then converted into a percentile based on age.

\section{Medical chart}

The medical chart recorded the infants' health history, including perinatal and neonatal data. Data on birth weight, gestational age, ultrasound examinations, maternal age, risk factors for gestation and delivery, and length of hospital stay were collected. Assessment of gestational age in the newborn infant was performed by using Capurro's method. This method works by evaluating five somatic factors and two neurological factors in the physical examination of the newborn. At the end, the professional adds the score and calculates the gestational age. With regard to clinical records, the Neonatal Medical Index (NMI) was performed; the NMI score ranged from 1 to $5^{23}$.

\section{Procedures}

Longitudinal data collection was carried out in four different age phases, from birth to eight months, as follows: neonatal, 2-4 months, 4-6 months and 6-8 months of corrected age for prematurity. Corrected age (CA) was calculated by subtracting from the chronological age the time left before term gestation (40 weeks). In the neonatal phase, the NAPI was applied at 32-37 weeks of PCA in the Intermediary Care Nursery setting. The assessment lasted on average 20 minutes. At 2-4 months CA, the DDST-II and TIMP were used. Finally, in both phases of $4-6$ and 6-8 months CA, the DDSTII and AIMS were administered. The assessments at ages 2 to 8 months of CA were conducted during one appointment (lasting around 40 minutes), in the Follow-up of High-Risk Infants Program at the Hospital of Goiania.

The assessment was carried out by eight trained physical therapists, supervised by the first author, who has expertise in all assessment instruments. The evaluations were video-recorded with a digital camera (Sony HC-40). Two examiners participated in each evaluation: one examiner performed the assessment of the infants and the other videorecorded the examination.

Two experts and independent coders analyzed the recorded videos, and scored the infants' performances. The coders were blinded to the infants' health history. The percentages of agreement were obtained for all instruments through the following formula: Agreement/(Agreement + Disagreement) $\mathrm{X} 100$. The results were as follows: $88 \%$ for the NAPI, $90 \%$ for the DDST-II, $80 \%$ for the TIMP and $81 \%$ for the AIMS.

In addition, the medical charts were reviewed to obtain the health history of the infants, focusing on the following perinatal and neonatal variables: delivery, birth weight, gestational age, Apgar at 5th min, neonatal illness and length of stay in the hospital. In addition, the neonatal clinical risk was assessed by NMI, including variables, such as birth weight, assisted ventilation, surgeries and intracranial haemorrhage.

\section{Statistical treatment analysis}

A statistical descriptive analysis was carried out. First, the association between the predictor variables (neurobehavioural development at 32-37 weeks of PCA, and perinatal and all neonatal variables referred to before) and the predictive development outcomes assessed by the DDST-II, TIMP and AIMS at different ages were examined 
using the Spearman correlation test. The perinatal and neonatal variables analysed were the following: birth weight, gestational age, Apgar at 5th min, neonatal disease, length of stay in the hospital and NMI score. The neurobehavioural development included seven clusters of the NAPI. Second, a binary logistic regression analysis was carried out on the performance of the DDST-II and a linear regression analysis on motor development outcomes (TIMP and AIMS). Only the predictor variables that presented statistically significant

\section{RESULTS}

\section{Characteristics of the study sample}

Table I shows that most of the sample were moderately or late preterm infants and had a low birth weight. The infants presented a low risk of morbidity and mortality according to the neonatal clinical risks of Apgar at the 5th min, and NMI scores. Otherwise, the sample study

Table 1: Characteristics of the study sample $(n=80)$ correlations with the outcomes variables were included in the predictive regression analyses. The Friedman test was used to compare the results on overall development at the three evaluated ages. The paired Student T-test was used to compare the outcomes of motor development. The Statistical Package for the Social Sciences (SPSS $\AA$, version 23.0, Chicago, IL, USA) was used for data analysis. The significance level for all tests was set at $5 \%(\mathrm{p} \leq 0.05)$.

presented around four diseases in the neonatal phase, such as, predominantly: neonatal respiratory distress syndrome (79\%), hyperbilirubinaemia (66\%), neonatal infection $(52 \%)$ and transitory tachypnoea of the newborn (46\%). On average, the neonates remained hospitalized for about a month after birth.

\begin{tabular}{|c|c|}
\hline Characteristics of the infants & Values \\
\hline \multicolumn{2}{|l|}{ Delivery - n (\%) } \\
\hline Normal & $34(42)$ \\
\hline Cesarean & $46(58)$ \\
\hline Birth weight (grams) - Mean (SD; range) & $1,715( \pm 437 ; 820-2,495)$ \\
\hline$<1500-\mathrm{n}(\%)$ & $28(35)$ \\
\hline$\geq 1500-\mathrm{n}(\%)$ & $52(65)$ \\
\hline Gestational Age (weeks) - Mean (SD; range) & $33.2( \pm 2.2 ; 27-36)$ \\
\hline$\leq 32-\mathrm{n}(\%)$ & $20(25)$ \\
\hline$>32-\mathrm{n}(\%)$ & $60(75)$ \\
\hline \multicolumn{2}{|l|}{ Neonatal Severity IIIness Risk - Mean (SD; range) } \\
\hline Apgar at 5 th minute (score)a & $8.3( \pm 1.4 ; 1-10)$ \\
\hline Neonatal Medical Index - NMI (score)b & $2.4( \pm 0,9 ; 1-5)$ \\
\hline Number of health complications & $3.6( \pm 1,8 ; 0-8)$ \\
\hline Length of time stay in hospital (days) - Mean (SD; range) & $29( \pm 20 ; 2-86)$ \\
\hline \multicolumn{2}{|c|}{ 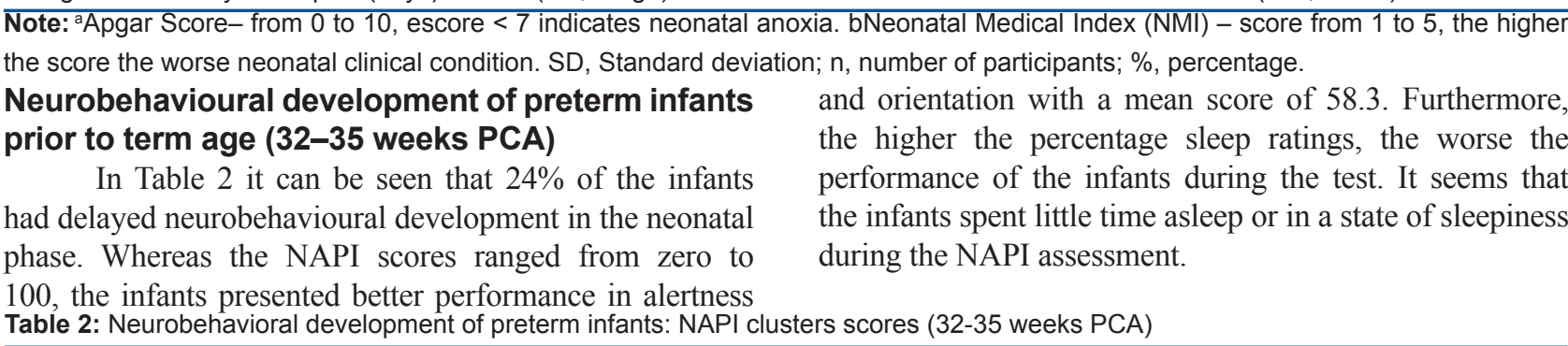 } \\
\hline Neurobehavioral Assessment ${ }^{\mathrm{a}}$ & Values \\
\hline \multicolumn{2}{|l|}{ NAPI Clusters -mean (SD; range) } \\
\hline Scarf sign & $45.4( \pm 22 ; 0-100)$ \\
\hline Motor development and vigor & $44.6( \pm 14.5 ; 20-84)$ \\
\hline Popliteal angle & $41.0( \pm 25.1 ; 0-100)$ \\
\hline Alertness and orientation & $58.3( \pm 19.5 ; 9-87)$ \\
\hline Irrritability & $38.1( \pm 25.7 ; 0-79)$ \\
\hline Cry quality & $37.5( \pm 39 ; 0-100)$ \\
\hline Percent sleep ratings & $38.3( \pm 32 ; 0-100)$ \\
\hline \multicolumn{2}{|l|}{ NAPI Classificationb - $f(\%)$} \\
\hline$S D<-1.0$ & $61(76)$ \\
\hline$S D \geq-1.0$ & $19(24)$ \\
\hline
\end{tabular}

Note: aNAPI - Neurobehavioral Assessment of Preterm Infant - Score from 0 (zero) to 100. The higher the score, the better the baby's performance on each item, except for the "sleep percentage" category. BNAPI Classification - according to the standard deviation of the normative data of the test sample. SD <-1.0 means delay. SD, standard deviation f, frequency; \%, Percent. 


\section{Development outcomes of preterm infants (2-8 months CA)}

In terms of overall development, Table 3 shows that $43 \%$ of the infants at $2-4$ months CA were at risk of developmental problems, decreasing to $35 \%$ at $4-6$ months $\mathrm{CA}$, and to $31 \%$ at $6-8$ months $\mathrm{CA}$, showing no statistical differences within the three age groups $(\mathrm{p} \leq 0.17)$. With specific regard to the assessment of motor development, the preterm infants showed $35-36 \%$ of delayed motor development at 2-8 months CA. The delay rate remained very similar in the development. There were no statistical differences within groups $(p>0.05)$.

Tabela 3: Classification of risk/delay of overall and motor development outcomes of preterm infants from 2-8 months of CA ( $n=80)$

\begin{tabular}{lc}
\hline Developmental outcomes at different age phases & $\mathbf{f}(\%)$ \\
\hline 2-4 months & $34(43 \%)$ \\
Risk on overall development (DDST-II) & $28(35 \%)$ \\
Delay motor development (TIMP) & $28(35 \%)$ \\
R-6 months & $29(36 \%)$ \\
Delay motor development (AIMS) & $25(31 \%)$ \\
6-8 months & $29(36 \%)$ \\
Disk on overall development (DDST-II) & \\
\hline
\end{tabular}

Note: aDevelopmental delay: Classification of Risk in overall development assessed by DDST-II; Below average (1.0 SD below the mean) for TIMP, according to normative data of the test; Abnormal (score < 10th percentile) for AIMS, according to the percentile rank. n, Number of participants; \%, percentage; CA, corrected age for prematurity; DDST-II, Denver Development Screening Test II; TIMP, Test of Infant Motor Performance; AIMS, Alberta Infant Motor Scale.

\section{Predictive models of development in preterm infants}

First, when examining the correlations between the predictor variables and the development of risk assessed by the DDST-II, it was detected that the development performance of preterm infants at 4-6 months CA was correlated with length of stay in the hospital $(r=0.26)$, alertness and orientation $(r=-0.35)$ and irritability $(r=$ $-0.22)$ NAPI scores. At 6-8 months CA, the development performance was associated only with the motor development and vigour NAPI score $(r=-0.22)$.

Examining the correlations between the predictor variables and the motor development at risk assessed by the
TIMP showed that at the age of 2-4 months CA the infants' performance correlated with the length of stay in hospital $(\mathrm{r}=-0.36)$, birth weight $(\mathrm{r}=0.31)$, and motor development and vigour $(\mathrm{r}=0.27)$, alertness and orientation $(\mathrm{r}=0.24)$, and irritability $(\mathrm{r}=0.26)$ and cry quality $(\mathrm{r}=0.24)$ NAPI scores. The motor development assessed by the AIMS showed that at the age of 4-6 months CA the infants' performance correlated with number of health complications $(r=-0.24)$. There were no statistically significant correlations between the infants' performance on the AIMS at 6-8 months, the neurobehavioural assessment and neonatal variables.

As can be seen in Table 4, the alertness and orientation in NAPI assessment explained $20 \%$ of the

Table 4: Regression models predicting overall (DDST-II) and motor (TIMP and AIMS) development in preterm infants at 2-8 months CA

\begin{tabular}{|c|c|c|c|c|c|c|}
\hline $\begin{array}{l}\text { Developmental outcomes at different } \\
\text { age phases (predictive variables) }\end{array}$ & Predictors variables & $\mathbf{R}^{2}$ & SE & B & OR/ $/ \beta$ & $p$ \\
\hline \multicolumn{7}{|l|}{ 2-4 months } \\
\hline \multirow[t]{2}{*}{ Motor development (TIMP) } & $\begin{array}{l}\text { Length time of stay in hospital } \\
\text { (days) }\end{array}$ & 0.12 & 0.098 & -0.242 & $\begin{array}{c}- \\
0.261^{a}\end{array}$ & 0.02 \\
\hline & $\begin{array}{c}\text { Motor development and vigor } \\
\text { (NAPI) }\end{array}$ & & 0.135 & 0.312 & $0.244^{a}$ & 0.02 \\
\hline \multicolumn{7}{|l|}{ 4-6 months } \\
\hline Overall development (DDST-II) & Alertness and orientation (NAPI) & 0.20 & 0.014 & -0.046 & $0.95^{\mathrm{b}, \mathrm{c}}$ & 0.001 \\
\hline Motor development (AIMS) & $\begin{array}{l}\text { Global development at 2-4 mon- } \\
\text { ths CA (DDST-II) }\end{array}$ & 0.04 & 0.123 & $\begin{array}{c}- \\
2.634\end{array}$ & $0.235^{a}$ & 0.04 \\
\hline \multicolumn{7}{|l|}{$6-8$ months } \\
\hline Overall development (DDST-II) & $\begin{array}{c}\text { Motor development and vigor } \\
\text { (NAPI) }\end{array}$ & 0.08 & 0.019 & 0.040 & $0.96^{b, d}$ & 0.04 \\
\hline \multirow[t]{2}{*}{ Motor development (AIMS) } & $\begin{array}{l}\text { Global development at } 2-4 \text { mon- } \\
\text { ths CA (DDST-II) }\end{array}$ & 0.08 & 1.66 & $\begin{array}{c}- \\
4.676\end{array}$ & $\begin{array}{c}- \\
0.304^{a}\end{array}$ & 0.006 \\
\hline & $\begin{array}{l}\text { Global development at } 4-6 \text { mon- } \\
\text { ths CA (DDST-II) }\end{array}$ & 0.09 & 1.708 & $\begin{array}{c}- \\
5.184\end{array}$ & $\begin{array}{c}- \\
0.325^{a}\end{array}$ & 0.003 \\
\hline
\end{tabular}


variance of the development risk of preterm infants at 4-6 months CA $(\mathrm{p} \leq 0.001)$. Lower alertness and orientation behaviour in the neonatal phase increased the chance of risk by $95 \%$ in the preterm infants' development at 4-6 months CA. In addition, at 6-8 months $\mathrm{CA}, 8 \%$ of the variance in the development risk of preterm infants was explained by motor development and vigour in the neonatal phase $(\mathrm{p} \leq$ 0.04 ). Lower motor development and vigour in the neonatal phase increased the chance of risk by $96 \%$ in development at 6-8 months CA.

The final predictive model accounted for $12 \%$ of the variance in the motor development in the TIMP assessment at $2-4$ months CA $(p=0.02)$. A greater length of stay in hospital decreased the score in the preterm infant

\section{DISCUSSION}

Preterm infants showed a $24 \%$ delay, that is, below the standard deviation, in the neurobehavioural assessment during the neonatal phase prior to term age in this study. This result is an important indicator of the adaptive state of the infant during their hospital stay. Even in a clinical stabilization period in the intermediate care unit, it is important to check the impact of the biological vulnerability generated by the premature birth in the neurological and behavioural responses of infants. This result corroborates a study with a larger sample in which $31 \%$ of the sample was detected as being at risk of subsequent developmental delay $^{30}$. The infants' highest score was obtained in the cluster alertness and orientation on the NAPI, such as in a recent study that explored the neurobehavioural aspects of preterm infants at different gestational ages ${ }^{15}$.

With regard to the infants' development according to the DDST-II, it was found that the infants had a $43 \%$ risk between 2 and 4 months. The risk decreased to $35 \%$ at 4 and 6 months and to $31 \%$ between 6 and 8 months CA. This shows that as infant's age, the risk decreases in overall motor development. This corroborates a study ${ }^{31}$ carried out with 1,363 Brazilian children who were suspected of developmental delay at 12 months of age. The DDSTII evaluates different aspects of development, and it is believed that with maturation the decrease of the delay rate is compensated for from one area to another.

However, in terms of motor development specifically, it was found that the percentage of delay remained unchanged as infants aged, with a $35 \%$ delay between 2 and 4 months and $36 \%$ at 4 and 8 months. This trend for delayed motor development may be associated with the large number of motor skill acquisitions in the first months of postnatal life. Through such behaviour, the infant can keep better visual control over the environment, greater contact with his/her body parts, increased control in handling objects and more interaction with parents. Motor skills from 2 to 8 months of age are related to postural control of the head and torso against gravity. In thisregard, low birth weight and prematurity can hinder muscle gain and the acquisition of muscle tone to enable the infant to remain sitting without support or in a prone position with weight discharge in the upper limbs. These findings are in line with a previous study ${ }^{31}$ in which it was shown that birth weight and prematurity can influence motor development. motor development. On the other hand, the higher motor development and vigour score on the NAPI increased the performance in motor development at 2-4 months CA.

The risk in the development of preterm infants at age 2-4 months was a predictor for the delay in motor development at 4-6 months CA $(p<0.036)$. Infants at risk of problems in development when assessed by the DDST-II at 2-4 months CA and 4-6 months CA had delayed motor development between 6-8 months CA.

In summary, the results revealed that neurobehavioural variables, hospital stay and overall delay are good predictors of motor development during the first year of age.

It is important to clarify that all families received guidance on how to promote and encourage the development of infants at home, but there was no professional intervention during the follow-up, since such care was not available at the referred to hospital.

The prediction model showed that a longer hospital stay and delayed motor development and vigour in the neonatal period increased the odds of preterm infants having delayed motor development between 2 and 4 months CCA by $24 \%$. The infants' responses during the neurobehavioural assessment in the neonatal period prior to term age were also associated with the subsequent motor development in a study carried out with Thai infants ${ }^{32}$.

Another study ${ }^{33}$ also showed an association between preterm birth and low birth weight and the length of stay in the NICU. The researchers evaluated 489 infants who remained in the NICU, of whom $28.42 \%$ (138) were born premature and 308 were underweight. The larger number of perinatal recurrences has presented a negative influence on preterm infants' development in cerebral palsy detection tests $^{34}$. In this regard the length of stay in hospital is a complex variable, as it involves several other associated factors that demonstrate infants' vulnerability towards environmental adversity.

The results of this study show that preterm infants who had delayed alertness and orientation in the neonatal period prior to term age were more likely to have developmental problems when they are between 4 and 6 months corrected age. Therefore, infants who performed worse in motor development and vigour in the neonatal period had a higher of for developmental problems between 6 and 8 months corrected age. In the alert period, the child interacts more with the environment from the motor and cognitive point of view, and uses the body to move and reach objects and people. The movements performed provide coordination to achieve more complex motor skills, such as rolling and sitting. Thus, the neurobehavioural assessment carried out in the neonatal period prior to term age can be considered a valuable prediction measure for developmental problems in follow-up services of infants born preterm and with low birth weight. The levels of alertness and vigour of an infant in the neonatal period may reflect both the maturation state of the infant and his/her adaptive responses to the extrauterine environment and to 
the hospital environment. Poor neurobehavioural responses may impact on the future development of the infant.

These findings corroborate a study ${ }^{24}$ that used the NAPI neurobehavioural assessment. In the mentioned study, the authors found that in variables such as alertness and orientation, motor development and vigour and irritability, the delay in the items related to alertness and orientation was higher in the infants who developed cerebral palsy and had sequelae than in those who did not have any motor sequelae. According to this study, delay in the neurobehavioural development as measured by the NAPI related to brain changes by functional magnetic resonance imaging had high sensitivity and specificity in the detection of delay and normality, respectively.

Thus, very early neurobehavioural assessment can be the first step in monitoring the development of infants born preterm, in terms of knowledge of the adaptive responses of the infant to hospital stay and adequate orientation and guidance of families in relation to follow-up programmes for infants at risk of developmental problems. A study has indicated that the neurobehavioural assessment carried out in the neonatal period is a relevant variable for problem detection in the development of infants in the long term ${ }^{24}$.

The prediction model for the development of infants between 6 and 8 months CCA revealed that the risk of overall motor development between 2 and 6 months increased the chance of delayed motor development between 6 and 8 months of age. Despite not being a specific instrument for the detection of delayed motor development, the DDSTII was able to indicate infants who showed more delayed motor development between 4 and 8 months corrected age.

The DDST-II has been used an instrument for developmental screening of preschool children, covers different areas and can be applied by any well-trained professional $^{35}$. In this study, the DDST-II is recognized as an instrument that is suitable for use with low-birthweight preterm infants, given that the operating costs for its application and scoring are much lower than those of other instruments, such as the TIMP and the AIMS. Therefore, the use of a global assessment tool can be very useful for professionals who wish to detect problems in preterm infants' early development, especially in paediatric outpatient clinics in developing countries ${ }^{36}$.

In the present study, motor development assessed by the AIMS and the TIMP were not good predictors of delay in subsequent development. Corroborating this study, a research carried out with preterm infants concluded that the use of the AIMS and TIMP at 3 months of age proved to be unable to predict the maturation of gross motor development and gait skills at 15 months of age ${ }^{14}$.

Based on the literature review, the findings in this study represent one more step forward in the knowledge about the effects of preterm birth on the health conditions and developmental outcome of such a vulnerable population in the short and medium term. It is worth taking into consideration the use of multiple measures and various instruments in the design, since it is recognized that child development is a product of the interaction of several biological and environmental factors.

This study analysed the development of infants based on many different aspects (global, motor and neurobehavioural ones) during the first year of postnatal life, which is the period considered to be decisive for the physical and mental health of the child. The investment in the survival of infants under adverse conditions of gestation, labour and birth should be reflected in studies that assess the impact of these conditions on subsequent development, emphasizing the first months of postnatal life. According to these authors, the assessment of infants in the first year provides a relevant base of indicators that can be used for intervention purposes, monitoring and prediction at older $\operatorname{ages}^{37,38}$.

This study has some limitations. In terms of the sample size, we lost a significant number of participants. However, it was noticed that the studied sample maintained the same characteristics as the eligible sample. Moreover, a control group of healthy preterm infants was not used and the cut-off points from the normative data of the research instruments themselves were used. There are still no standardized data for Brazilian healthy preterm infants with the NAPI, TIMP, AIMS and DDST-II.

Nevertheless, the present study showed key strengths as it focused on a very early assessment of preterm infants' neurodevelopment and demonstrated the predictive value of these indicators in the subsequent development during their first year of life. These findings reinforce prevention strategies in the developmental care of a biologically and socially vulnerable sample.

In conclusion, the study revealed that neurobehavioural variables, length of hospital stay and overall developmental delay are good predictors of motor development in the first year of preterm infants.

\section{Financial support}

This study was supported by the Conselho Nacional de Desenvolvimento Científico e Tecnológico (CNPq), to C.K.M.R.F. (Process 142268/2005-4) and, M.B.M.L (Process 302001/2004-2).

\section{REFERENCES}

1. Kiechl-Kohlendorfer U, Ralser E, Pupp Peglow U, Reiter G, Trawöger R. Adverse neurodevelopmental outcome in preterm infants: risk factor profiles for different gestational ages. Acta Paediatr. 2009;98(5):792-6. DOI: http://dx.doi.org/10.1111/j.1651-2227.2009.01219.x

2. Evensen KA, Skranes J, Brubakk AM, Vik T. Predictive value of early motor evaluation in preterm very low birth weight and term small for gestational age children. Early Hum Dev. 2009;85(8):511-8. DOI: http://dx.doi.org/10.1016/j.earlhumdev.2009.04.007

3. Wolf MJ, Koldewijn K, Beelen A, Smit B, Hedlund R, de Groot IJ. Neurobehavioral and developmental profile of very low birthweight preterm infants in early infancy. Acta Paediatr. 2002;91(8):930-8. 
DOI: http://dx.doi.org/10.1111/j.1651-2227.2002.tb02858.x

4. World Health Organization (WHO). Born too soon: the global action report on preterm birth. Geneva: World Health Organization; 2012.

5. Salt A, Redshaw M. Neurodevelopmental follow-up after preterm birth: follow up after two years. Early Hum Dev. 2006;82(3):185-97. DOI: http://dx.doi.org/10.1016/j.earlhumdev.2005.12.015

6. Hack M. Survival and neurodevelopmental outcomes of preterm infants. J Pediatr Gastroenterol Nutr. 2007;45(3): S141-2. DOI: http://dx.doi.org/10.1097/01.mpg.0000302959.55428.05

7. Marret S, Ancel PY, Marpeau L, Marchand L, Pierrat V, Larroque B, et al. Neonatal and 5-year outcomes after birth at 30-34 weeks of gestation. Obstet Gynecol. 2007; 110(1):72-80. DOI: http://dx.doi.org/10.1097/01.AOG.0000267498.95402.bd

8. Pin TW, Darrer T, Eldridge B, Galea MP. Motor development from 4 to 8 months corrected age in infants born at or less than 29 weeks' gestation. Dev Med Child Neurol. 2009;51(9):739-45. DOI: http://dx.doi.org/10.1111/j.1469-8749.2009.03265.x

9. Latal B. Prediction of neurodevelopmental outcome after preterm birth. Pediatr Neurol. 2009;40(6)413-9. DOl: http://dx.doi.org/10.1016/j.pediatrneurol.2009.01.008

10. Arditi-Babchuk H, Feldman R, Eidelman Al. Rapid eye movement (REM) in premature neonates and developmental outcome at 6 months. Infant Behav Dev. 2009; 32(1):27-32. DOI: http://dx.doi.org/10.1016/j.infbeh.2008.09.001

11. Badr LK, Bookheimer S, Purdy I, Deeb M. Predictors of neurodevelopmental outcome for preterm infants with brain injury: MRI, medical and environmental factors. Early Hum Dev. 2009; 85(5):279-84. DOI: http://dx.doi.org/10.1016/j.earlhumdev.2008.11.005

12. Janssen AJ, Nijhuis-van der Sanden MW, Akkermans RP, Tissingh J, Oostendorp RA, Kollée LA. A model to predict motor performance in preterm infants at 5 years. Early Hum Dev. 2009;85(9):599-604. DOI: http://dx.doi.org/10.1016/j.earlhumdev.2009.07.001

13. Luu TM, Ment LR, Schneider KC, Katz KH, Allan WC, Vohr BR. Lasting effects of preterm birth and neonatal brain hemorrhage at 12 years of age. Pediatrics. 2009; 123(3):1037-44. DOI: http://dx.doi.org/10.1542/peds.2008-1162

14. Nuysink J, Van Haastert IC, Eijsermans MJ, Koopman-Esseboom C, Helders PJM, Vries LS, et al. Prediction of gross motor development and independent walking in infants born very preterm using the Test of Infant Motor Performance and the Alberta Infant Motor Scale. Early Hum Dev. 2013; 89(9):693-7. DOI: http://dx.doi.org/10.1016/j.earlhumdev.2013.04.016

15. Gorzilio DM, Garrido E, Gaspardo CM, Martinez FE, Linhares MBM. Neurobehavioral development prior to term-age of preterm infants and acute stressful events during neonatal hospitalization. Early Hum Dev. 2015;91(12):769-75. DOI: http://dx.doi.org/10.1016/j.earlhumdev.2015.09.003

16. Tieman BL, Palisano RJ, Sutlive AC. Assessment of motor development and function in preschool children. Ment Retard Dev Disabil Res Rev. 2005;11(3):189-96. DOI: http://dx.doi.org/10.1002/ mrdd.20074

17. Maitre NL, Slaughter JC, Aschner JL. Early prediction of cerebral palsy after neonatal intensive care using motor development trajectories in infancy. Early Hum Dev. 2013;89(10):781-6. DOI: http://dx.doi.org/10.1016/j.earlhumdev.2013.06.004

18. Majnemer A, Snider L. A comparasion of developmental asssessments of the newborn and young infant. Ment Retard Dev Disabil Res Rev 2005;11(1):68-73. DOI: http://dx.doi.org/10.1002/mrdd.20052

19. Fjørtoft T, Grunewaldt KH, Løhaugen GC, Mørkved S, Skranes J, Evensen KA. Assessment of motor behaviour in high-risk-infants at 3 months predicts motor and cognitive outcomes in 10 years old children. Early Hum Dev. 2013;89(10):787-93. DOI: http://dx.doi.org/10.1016/j.earlhumdev.2013.06.007

20. Potijk MR, Kerstjens JM, Bos AF, Reijneveld SA, Winter AF. Developmental delay in moderately preterm-born children with low socioeconomic status: risks multiply. J Pediatr. 2013;163(5):1289-95. DOI: http://dx.doi.org/10.1016/j.jpeds.2013.07.001

21. Simard MN, Luu TM, Gosselin J. Concurrent validity of ages and stages Questionnaires in preterm infants. Pediatrics. 2012; 130;e108. DOI: http://dx.doi.org/ 10.1542/peds.2011-3532

22. Bornstein $\mathrm{MH}$, Hendricks $\mathrm{C}$. Screening for developmental disabilities in developing countries. Soc Sci Med. 2013; 97:307-15. DOI: http://dx.doi.org/ 10.1016/j.socscimed.2012.09.049

23. Korner AF, Browns JV, Thom VA, Constantinou JC. The neurobehavioral assessment of the preterm infant. Manual revised. 2nd ed. Van Nuys: Child Development Media; 2000.

24. Constantinou JC, Adamson-Macedo EM, Mirmiran M, Fleisher BE. Movement, imaging and neurobehavioral assessment as predictors of cerebral palsy in preterm infants. J Perinatol. 2007;27(4):225-9. DOI: http://dx.doi.org/10.1038/sj.jp.7211664

25. Frankenburg WK, Dodds JB, Archer P, Shapiro H, Bresnick B. The Denver II: a major revision and restandardization of denver developmental screening test. Pediatrics. 1992; 89(1):91-7.

26. Campbell SK, Kolobe THA, Osten ET, Lenke M, Girolami G. Construct validity of the test of infant motor performance. Test user's manual version 1.4. Campbell; 2001.

27. Campbell SK, Kolobe THA, Wright B, Linacre JM. Validity of Test of Infant Motor Performance for prediction of 6, 9 and 12 month scores on the Alberta Infant Motor Scale. Dev Med Child Neurol. 2002; 44(4): 263-72. DOI: http://dx.doi.org/ 10.1111/j.1469-8749.2002.tb00802.x

28. Piper MC, Darrah J. Motor assessment of the developing infant. EUA: Saunders Company; 1994.

29. Darrah J, Piper MC, Watt M. Assessment of gross motor skills of at-risk infants: predictive 
validity of the Alberta Infant Motor Scale. Dev Med Child Neurol. 1998;40 (7):485-91.

DOI: http://dx.doi.org/ 10.1111/j.1469-8749.1998.tb15399.x

30. Gabriel PSZ, Formiga CKMR, Linhares MBM. Early neurobehavioral development of preterm infants. Psicol Reflex Crit. 2013;26(1):202-11. DOI: http://dx.doi.org/10.1590/S0102-79722013000100022

31. Halpern R, Giugliani ER, Victora CG, Barros FC, Horta BL. Risk factors for suspicion of developmental delays at 12 months of age. J Pediatr. 2000;76(6):421-8. DOI: http://dx.doi.org/10.1111/j.1365-3016.2010.01115.x

32. Lekskulchai $\mathrm{R}$, Cole $\mathrm{J}$. The relationship between the scarf ratio and subsequent motor performance in infants born preterm. Pediatr Phys Ther. 2000;12(4):150-7.

33. Afrasiabi N, Mohagheghi P, Kalani M, Mohades G, Farahani Z. The Effect of High Risk Pregnancy on Duration of Neonatal Stay in Neonatal Intensive Care Unit. Iran J Pediatr. 2014;24(4):423-28.

34. Van Schie PE, Becher JG, Dallmeijer AJ, Barkhof F, Van Weissenbruch MM, Vermeulen RJ. Motor testing at 1 year improves the prediction of motor and mental outcome at 2 years after perinatal hypoxic-ischaemic encephalopathy. Dev Med Child Neurol. 2010;52(1):54-9. DOI: http://dx.doi.org/10.1111/j.1469-8749.2009.03302.x

35. Macy M. The evidence behind developmental screening instruments. Infants Young Children. 2012;25(1):19-61. DOI: http://dx.doi.org/10.1097//YC.0b013e31823d37dd

36. Formiga CKMR, Vieira MEB, Linhares MBM. Avaliação do desenvolvimento de bebês nascidos prétermo: a comparação entre idades cronológica e corrigida. J Hum Growth Dev. 2015; 25(2):230-6. DOI: http://dx.doi.org/10.7322/JHGD.103020

37. Vohr BR, O'Shea M, Wright LL. Longitudinal multicenter follow-up of high-risk infants: why, who, when, and what to assess. Semin Perinatol. 2003;27(4):333-42. DOI: https://doi.org/10.1016/S0146-0005(03)00045-4

38. Oliveira C, Castro L, Silva R, Freitas I, Gomes M, Candida M. Factors associated with the development of preterm children at four and eight months of corrected gestational age. J Hum Growth Dev. 2016; 26(1):41-7. DOI: http://dx.doi.org/10.7322/jhgd.110024

\section{Resumo}

Introdução: O lactente prematuro é vulnerável a apresentar atrasos no desenvolvimento. Detectar problemas na idade precoce é um dos desafios de profissionais e pesquisadores da área.

Objetivo: Analisar o desenvolvimento motor e identificar os fatores de risco associados aos desfechos preditores de atraso geral e motor em recém-nascidos pré-termo.

Método: Foram avaliados 80 recém-nascidos prematuros $(50 \%$ do sexo feminino, média de idade gestacional $=33 \pm 2,2$ semanas) com baixo peso ao nascer (média de $1.715 \mathrm{~g} \pm 437$ ), avaliados pela Avaliação Neurocomportamental do Bebê Pré-termo (NAPI) durante a fase neonatal (antes do termo), Teste de Desenvolvimento de Denver II entre 2-8 meses, Teste de Desempenho Motor Infantil entre 2-4 meses, e Escala Motora Infantil de Alberta entre 4-8 meses.

Resultados: $O$ atraso neurocomportamental foi observado em $24 \%$ dos lactentes na fase neonatal. Entre 2-8 meses, o atraso no desenvolvimento geral foi $\geq 31 \%$ e o atraso no desenvolvimento motor foi de $35-36 \%$. Diminuição dos níveis de alerta, orientação, desenvolvimento motor e vigor de acordo no NAPI mostraram ser preditivos de atraso no desenvolvimento entre 4-6 meses de idade. O atraso no desenvolvimento geral entre 2-6 meses foi preditivo de atraso no desenvolvimento motor entre 6-8 meses.

Conclusão: As variáveis neurocomportamentais, tempo de internação hospitalar e atraso no desenvolvimento geral são bons preditores de desenvolvimento motor no primeiro ano de idade.

Palavras-chave: pré-termo, desenvolvimento motor, lactentes, modelo preditivo

${ }^{\oplus}$ The authors (2017), this article is distributed under the terms of the Creative Commons Attribution 4.0 International License (http://creativecommons.org/licenses/by/4.0/), which permits unrestricted use, distribution, and reproduction in any medium, provided you give appropriate credit to the original author(s) and the source, provide a link to the Creative Commons license, and indicate if changes were made. The Creative Commons Public Domain Dedication waiver (http://creativecommons.org/publicdomain/ zero/1.0/) applies to the data made available in this article, unless otherwise stated. 